\section{The Indigenous Food Circle: Reconciliation and resurgence through food in Northwestern Ontario}

\author{
Charles Z. Levkoe ${ }^{a *}$ and Lana Ray ${ }^{\mathrm{b}}$ \\ Lakehead University \\ Jessica Mclaughlin ${ }^{\mathrm{c}}$ \\ Indigenous Food Circle
}

\section{Special JAFSCD Issue \\ Indigenous Food Sovereignty in North America \\ sponsored by

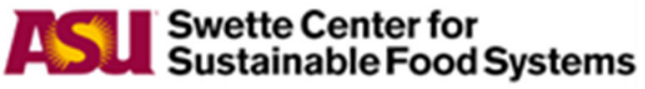 \\ Arizona State University}

Submitted January 16, 2019 / Revised March 8 and April 6, 2019 / Accepted April 7, 2019 /

Published online October 15, 2019

Citation: Levkoe, C. Z., Ray, L., \& Mclaughlin, J. (2019). The Indigenous Food Circle: Reconciliation and resurgence through food in Northwestern Ontario. Journal of Agriculture, Food Systems, and Community Development, 9(Suppl. 2), 101-114. https://doi.org/10.5304/jafscd.2019.09B.008

Copyright (C) 2019 by the Authors. Published by the Lyson Center for Civic Agriculture and Food Systems. Open access under CC-BY license.

\begin{abstract}
Food policy councils provide a forum to address food systems issues and a platform for coordinated action among multisectoral stakeholders. While diverse in structure, most councils aim to develop democratic and inclusive processes to evaluate, influence, and establish integrated policy and

a * Corresponding author: Charles Z. Levkoe, Canada Research Chair in Sustainable Food Systems, Department of Health Sciences, Lakehead University; 955 Oliver Road; Thunder Bay, Ontario P7B 5E1 Canada; +1-807-346-7954;

clevkoe@lakeheadu.ca

b Lana Ray, Department of Indigenous Learning, Lakehead University; 955 Oliver Road; Thunder Bay, Ontario P7B 5E1 Canada; 1ray@lakeheadu.ca

c Jessica Mclaughlin, Coordinator, Indigenous Food Circle; jessicamclaughlin82@gmail.com
\end{abstract}

programs for healthy, equitable, and sustainable food systems. The Thunder Bay and Area Food Strategy (TBAFS) is one such example that promotes regional food self-reliance, healthy environments, and thriving economies through the

\section{Disclosures}

The three authors have been involved with the development, ongoing governance, and research with the Indigenous Food Circle. Charles Levkoe and Lana Ray received research funding to support the development of the Indigenous Food Circle, and Jessica Mclaughlin worked as a paid co-coordinator for eight months leading up to the completion of this paper. These relationships are all discussed explicitly in the text of the essay.

\section{Funding Disclosure}

We acknowledge the financial support of the Social Science and Research Council of Canada. 
implementation of research, planning, policy, and program development. Despite its success, the TBAFS had no formal engagement from the Indigenous communities that make up almost 13\% of Thunder Bay's population (the highest urban Indigenous population in Canada). Recognizing this gap, in 2016, members of the TBAFS began to develop partnerships with regional Indigenous leaders and organizations to better understand the barriers and opportunities to engagement. The result was the establishment of the Indigenous Food Circle, which aimed to reduce Indigenous food insecurity, increase food self-determination, and establish meaningful relationships with the settler population through food. In this paper, we trace the history of the Indigenous Food Circle. Drawing on theories of decolonization and Indigenous food sovereignty, we argue that the Indigenous Food Circle requires more than simply goodwill from TBAFS members and other allied organizations. It demands confronting our histories and engaging in action that transforms current patterns of relations. It means embracing the discomfort that comes with recognizing the prevalence of settler colonialism and developing respectful and just relationships followed by action. We conclude with some suggestions for continuing this work and the opportunity to experiment with food as a tool for reconciliation and resurgence.

\section{Keywords}

Food Policy Council, Food Security, Food Sovereignty, Fort William First Nation, Indigenous Food Circle, Robinson Superior Treaty 1850, SelfDetermination, Social Justice, Thunder Bay

$$
\begin{aligned}
& \text { We believe that traditional knowledge, as well as } \\
& \text { addressing the social determinants of health, should } \\
& \text { be at the heart of food policies and practices of govern- } \\
& \text { ments. Indigenous peoples in different areas have sus- } \\
& \text { tained themselves on the wildlife and plants that their } \\
& \text { areas have produced. Various forms of agriculture } \\
& \text { have been practiced by Indigenous peoples in order to } \\
& \text { sustain the soil and land. This knowledge has been } \\
& \text { used by Indigenous peoples and in many cases shared } \\
& \text { with their non-native brothers and sisters. The uses of } \\
& \text { plants and animals as medicines and foods were } \\
& \text { common among Indigenous peoples. This unique }
\end{aligned}
$$

\begin{abstract}
knowledge belonging to Indigenous peoples has also assisted the Canadian people to live on the land and to prosper.

—Excerpt from Food Secure Canada's People's Food Policy (2011, p. 6)
\end{abstract}

\section{Introduction}

The food we eat provides nourishment for our bodies and our minds. More than just fuel, food is a part of our identities and cultures, and connects us to the natural world. When thinking about food, it is imperative that we also consider the social, political, economic, and spiritual contexts of land within our communities at multiple and intersecting scales. For example, issues of power surrounding land access, ownership, and rights directly impact food security and food sovereignty. The idea of a food system describes these relationships that bring food to our plates-from harvesting, foraging, and growing food to processing, distribution, consumption, and waste. Building on existing food systems definitions that offer broader explanations (see for example Ericksen, 2008), the PanCanadian Indigenous Food Systems Network (n.d.) describes food systems as:

The vast myriad of rivers, watersheds, landforms, vegetation and climatic zones [that] have worked together for thousands of years to shape and form Indigenous land and food systems. Consisting of a multitude of natural communities, Indigenous food systems include all of the land, air, water, soil and culturally important plant, animal, and fungi species that have sustained Indigenous peoples over thousands of years (p. 3).

In Canada, settler colonialism has worked acutely and systematically to disrupt and alter Indigenous peoples' relationships with land in an effort to secure and maintain resources, power, and control (Ray et al., 2019). Thus, it is impossible to engage in food systems praxis without acknowledging the historical and ongoing theft of land, broken treaties, and anti-Indigenous racism (Kepkiewicz et al., 2015). Since the arrival of European settlers to what is now referred to as North America in the 
$16^{\text {th }}$ century, Indigenous peoples have been violently removed from their lands, displaced from their food systems, and forced to assimilate into the dominant settler colonial culture. This includes being forced off traditional territories onto reservations and losing cultural and intergenerational knowledge through the residential school system, which was run by the government in partnership with Christian churches and their missionary societies (Milloy, 1999; Ray et al., 2019). The diverse Indigenous traditions around food have been treated with contempt by settler governments and viewed as detrimental to colonial notions of progress and development.

Settler colonialism continues to deny Indigenous people's access to Traditional territories as a deliberate attempt at erasure of Indigenous identity, culture, and sovereignty (Daschuk, 2013; Manuel \& Derrickson, 2015). According to Wawakapewin First Nation Elder Simon Frogg, "As a result of these treaty relations, Aboriginal peoples have been taken advantage of and have not been given what the government promised them. This has led to us losing our way of life and our land" (quoted in Robidoux, Leblanc, \& Mason, 2017, p. XV). Yet, remarkably, after more than 500 years of settler colonialism, Indigenous peoples remain actively engaged in efforts to protect and revitalize land and waters and to restore Traditional food systems, including cultivation, fishing, hunting, and foraging (Morrison, 2011; Rudolph \& McLachlan, 2013).

While there are opportunities for Indigenous movements to work more closely with existing collaborative food networks on projects related to protecting and revitalizing land and food systems, critics have argued that settler food movements must fundamentally alter the dominant perceptions of food activism (Levkoe, 2011). Particularly, they must critically interrogate oppressive structures that include capitalism, patriarchy, white supremacy, and colonialism (Kepkiewicz et al., 2015) and learn from Indigenous food sovereignty efforts (Grey \& Patel, 2015; Martens, Cidro, Hart, \& McLachlan, 2015; Matties, 2016) that are rooted in a range of different social and ecological contexts. According to Food Secure Canada (2011) that guided the Pan-Canadian People's Food Policy ${ }^{1}$ in 2011,

As a result of harmony in our food systems, Indigenous peoples exemplified food sovereignty. Thus, the current efforts within the rapidly expanding Indigenous food sovereignty movement to restore and enhance access to traditional Indigenous foods in the forests, fields and waterways continue to be linked to the historic claims to the hunting, fishing and gathering grounds in their respective traditional territories. . . . the trends occurring amongst Indigenous peoples are the beginnings of a new Indigenous food sovereignty. By establishing their own projects under their own leadership, Indigenous peoples are determining what should be grown, cooked, taught, and shared. In time, these decisions will pave the way for greater food security. (p. 4)

While the field of sustainable food systems studies has expanded dramatically over the past decade, there remains a major gap in research and practice surrounding Indigenous food sovereignty in the context of Indigenous and settler relations, especially within an urban Canadian context. Whereas the vast majority of literature is concentrated on Indigenous peoples' responsibilities and roles in Indigenous food sovereignty, this paper emphasizes a model of interrelational responsibilities among Indigenous peoples and settlers. This is a necessary lens, considering the ongoing impacts of interference and measures of control imposed on Indigenous peoples by settler cultures and governments.

In this paper, we focus on the establishment of the Indigenous Food Circle and its efforts to address issues of sustainable food systems, social justice, and Indigenous food sovereignty in the Thunder Bay area. The city of Thunder Bay is

\footnotetext{
1 The People's Food Policy was Canada's first and (to date) only collaborative and comprehensive food policy; it was developed between 2008 and 2011. This Pan-Canadian initiative mobilized over 3,500 people through a grassroots initiative to develop a food sovereignty policy platform and vision for the food sovereignty movement (see Levkoe \& Sheedy, 2019).
} 
located on the Traditional lands of Fort William First Nation, signatory to the Robinson Superior Treaty of 1850. The Indigenous Food Circle's evolution is rooted in principles of food sovereignty and the success and limits of the Thunder Bay and Area Food Strategy's (TBAFS) engagement with Indigenous peoples. The TBAFS is a regional food policy council that aims to address food systems issues and acts as a platform for coordinated action among multisectoral stakeholders. Established in 2008 , its goal is to promote regional food selfreliance, healthy environments, and thriving economies through the implementation of research, planning, policy, and program development. Despite its success, the TBAFS had no formal engagement from Indigenous communities in Thunder Bay, a city with the highest urban Indigenous population in Canada. Recognizing this gap, in 2016 a partnership between TBAFS members and regional Indigenous leaders and organizations led to the establishment of the Indigenous Food Circle. Initially, this was an attempt to better understand the barriers and opportunities to engagement, but it has led to a more comprehensive effort to enhance Indigenous food sovereignty across Northwestern Ontario. The relationships and work conducted through the Indigenous Food Circle emphasized and encouraged a means of shared responsibility; however, this is just the beginning, and far more work is required for food sovereignty to become a reality.

The objectives of this paper are to recount the establishment of the Indigenous Food Circle in relation to some of the broader scholarship and experiences of decolonization and Indigenous food sovereignty in Northwestern Ontario. It is our intention to celebrate its successes, but also identify some of the tensions that arose among the membership and with the broader community. We write this paper as three individuals who played a leadership role in the development of the Indigenous Food Circle. Charles Levkoe is a settler raised in Southern Ontario, a scholar-activist deeply engaged in community-based action research, social justice, and food sovereignty work; he is an executive member of the TBAFS. Lana Ray is an Anishinaabe scholar and activist from Opwaaganasiniing whose ongoing work is rooted in resurgent and decolonial praxis. Jessica Mclaughlin is an Anishinaabe community developer from Long Lake 58 First Nation and is an executive member of the TBAFS. Jessica also worked as a coordinator of the Indigenous Food Circle. The integrative methodological approach to writing this paper combines both Indigenous and western ways of knowing (see, for example, Martin, 2012). Our collective reflections are based on our own experiences working with the TBAFS and the Indigenous Food Circle as well as our ongoing engagement with Indigenous-led and Indigenous-serving organizations in the Thunder Bay area and beyond. The insights in this paper also draw on group discussions at quarterly Indigenous Food Circle meetings, along with a series of unstructured interviews with representatives from the member organizations about their visions for the emerging alliance. In addition, we draw from our ongoing research and engagement on issues of settler colonialism, sustainability, social and ecological justice, and food sovereignty.

\section{Indigenous and Settler Relations in the Thunder Bay Area: Treaty-Making, Settler Colonialism, and Racism}

As stated in the introduction, any discussions of food systems in Canada must consider issues of settler colonialism and the political and economic relationships with the land and water. Thunder Bay is located in Northwestern Ontario on the Traditional Territory of the Anishinaabe peoples of Fort William First Nation (see Figure 1). Through the Robinson Superior Treaty (1850), the British secured lands for settlement and development in excess of 40,000 square kilometers (15,444 square miles) (Sinclair, 2018). In exchange, the treaty guaranteed reserve lands, hunting and fishing rights, and annuities for the Anishinaabe people.

Treaty agreements have not been upheld on the part of the British and their subjects (Sinclair, 2018, p. 4), and settler occupation in and around Thunder Bay has had a direct impact on Anishinaabe food sovereignty. Occupation, enclosure, and use of Traditional territory, as well as the imposition of regulation by settler governments, have limited and denigrated hunting, trapping, and fishing grounds (Fort William First Nation [FWFN], 


\section{Figure 1. Fort William First Nation Traditional Territory}

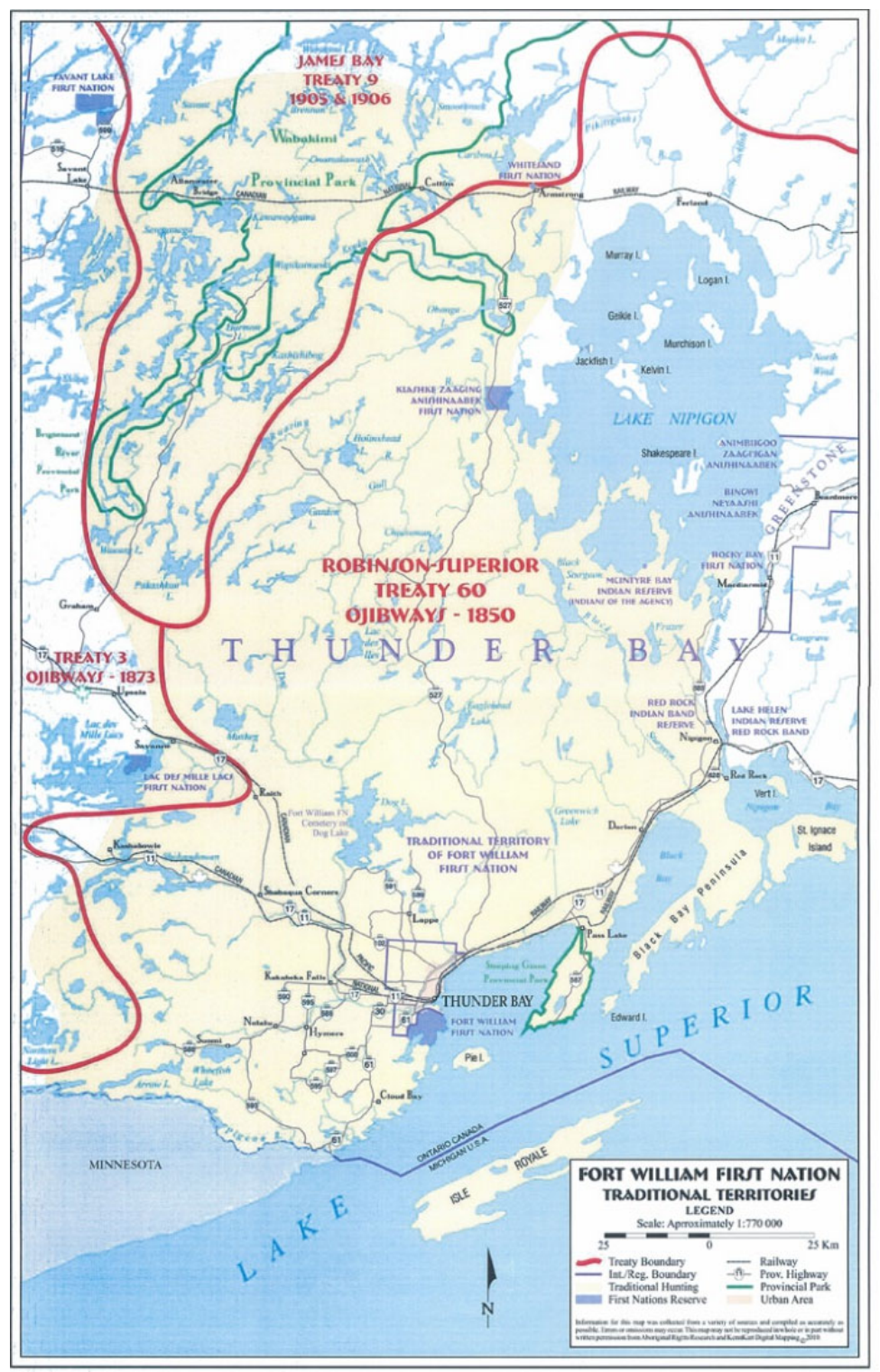

Source: Fort William First Nations.

2019). Vast amounts of reserve lands that were created under the provisions of the Robinson-

Superior Treaty have been expropriated for use by industry and the state. The expropriation of lands has been traumatic for the people of Fort William First Nation (McNeilly, 2018), who have been displaced from their homes and all arable lands (Sinclair, 2018; FWFN, 2019).

Prior to the land expropriation, members of Fort William First Nation were quite successful in their agricultural endeavors, including raising cattle, growing vegetables, and harvesting berries. For example, members won prizes at the Port Arthur Agricultural fair, and by 1900, 40 farmsteads that comprised over 600 acres (243 hectares) of cleared land could be found along the banks of the Kaministiquia River (FWFN, 2019). In 1859, farmland in what is now referred to as Neebing Township was surrendered to the Crown for future use, and in 1905 Fort William First Nation was subject to the single largest land expropriation by a railway in Canadian history (FWFN, 2019). At this time, a more than 1,600-acre (648hectare) land surrender was imposed so that the Grand Trunk Pacific Railway could build a terminus for grain (FWFN, 2019; McNeilly, 2018). This infrastructure was never fully built, and less than 10 years later, the lands were used by settler farmers for cattle grazing (FWFN, 2019).

Despite systematic efforts to unsettle Anishinaabe peoples from Thunder Bay and the surrounding area, approximately a thousand members of Fort William First Nation live on-reserve. The city of Thunder Bay now has the highest percentage of urban Indigenous residents in Canada, about 13\% of the population according to Statistics Canada (2017a). Moreover, as a regional hub, many Indigenous peoples traveling from reserves around Northwestern Ontario stay in the city temporarily to visit family and friends, seek employment, attend school and/or post-secondary institutions, and access health and social services. Many of these individuals are from First Nations communities with a similar history of land dispossession and broken treaty agreements, who face deep antiIndigenous racism.

While Indigenous peoples' presence is indicative of their resilience, the persistence of settler colonialism has greatly affected communities that experience racism, high rates of poverty, poor health, lack of education, and limited access to 
public services (Council of Canadian Academics, 2014; Power, 2008). Elsheikh (2016) notes that addressing issues of justice, including income, employment, and the unjust treatment of racialized people by government institutions, is a necessary precursor to building more sustainable and equitable food systems. For example, while direct links between poverty and food sovereignty may be more readily apparent, Pellow (2016) urges environmental justice researchers and practitioners to acknowledge the existence of connections between environmental justice and police violence. He explains that it is rare to find the existence of circumstances to address injustices when populations are marked for erasure and death.

In Thunder Bay, over half the Indigenous population lives below the Low-Income Measure, compared to only $9 \%$ of non-Indigenous residents (Lakehead Social Planning Council, 2018). Indigenous peoples in Thunder Bay are also less likely to complete post-secondary education and are more likely to have higher unemployment rates in comparison to the settler population (McNeilly, 2018), with Indigenous unemployment rates at approximately 20\% (City of Thunder Bay, 2015). With inequities such as poverty as a primary contributing factor to food access (Howard \& Edge, 2013), food insecurity levels are highest among Indigenous peoples in Thunder Bay and the surrounding area. This is consistent with Canada as a whole, as Indigenous peoples are much more likely to be food-insecure than the settler population, with over $20 \%$ of off-reserve Indigenous households experiencing food insecurity (Howard \& Edge, 2013).

Indigenous peoples in Thunder Bay also experience direct and systemic racism on a daily basis (Sinclair, 2018). Many Indigenous peoples in the city have experienced intimidation and violence, including racist remarks, threats, physical assault, and even death. For example, the city of Thunder Bay has among the highest homicide rates $(5.80$ homicides per 100,000 population) and hate crime rates (140.7 on the Violent Crime Severity Index) in the country (Statistics Canada, 2017b). The Grassroots Committee on Native Unsolved Murders, formed in the 1990s, identified more than 30 suspicious deaths of Indigenous people where thorough investigations were not conducted
(McNeilly, 2018). Decades later, the same issues persist. In 2015/16, a Coroner's Inquest into the deaths of seven First Nations youths who died under suspicious circumstances in Thunder Bay was held, and in 2016, a complaint was filed with the Office of the Independent Police Review Director (OIPRD) regarding the 2015 death of Stacy DeBungee, an Indigenous man. In the complaint, community members and leaders alleged that "police devalued Indigenous lives, reflected differential treatment, and were based on racist attitudes and stereotypical preconceptions about Indigenous people" (McNeilly, 2018, p. 5).

In December 2018, the OIPRD's report, Broken Trust: Indigenous People and the Thunder Bay Police Service, concluded that systemic racism does exist within the Thunder Bay Police force at an institutional level (McNeilly, 2018). In the same week, Senator Murray Sinclair, the lead investigator into the Ontario Civilian Police Commission's investigation of the Thunder Bay Police Services Board (a civilian oversight board for the police force) made a similar observation. Senator Sinclair concluded that "the evidence is overwhelming that Indigenous peoples in Thunder Bay have been subject to differential policing standards for decades" and that "the Police Service Board has failed to serve the Indigenous community in Thunder Bay" (Sinclair, 2018, p. 73). These reports confirmed what many Indigenous people in Thunder Bay had been saying for some time - that policing in the city is steeped in systemic racism that has served to maintain the settler colonial system. This context serves as a reminder of the realities that shape food systems, along with the realities of pursuing Indigenous food sovereignty in Thunder Bay and Canada more broadly.

\section{The Thunder Bay and Area Food Strategy}

The dominant approaches to bringing food to people have focused on increasing profit through processes of neoliberalization (Penchlaner \& Otero, 2010; Lawrence et al., 2013) and productivism (Rosin, 2013). These highly concentrated and technocratic processes have been widely criticized as contributing to the seemingly intractable challenges concerning health and wellbeing, ecosystem integrity, waste and pollution, and poverty (Frison, 
2016; IAASTD, 2009; Lang \& Heasman, 2015). Current settler colonial policy frameworks in the global north, with few exceptions, consider these as collateral problems and respond to them through fragmented approaches that treat symptoms rather than analyzing and responding to structural issues (Dowler \& O’Connor, 2012; MacRae, 2011; Rideout, Riches, Ostry, Buckingham, \& MacRae, 2007). For example, the problem of hunger is often addressed as a result of scarcity as opposed to a problem of inequity. Research has demonstrated that food insecurity is directly related to incomeas a household's income declines, the risk of food insecurity increases (Dachner \& Tarasuk, 2018). Top-down policy approaches tend to overlook onthe-ground realities and ignore the needs and priorities of people and communities in favor of economic gain for corporations. This has led to a legitimacy crisis: the widespread public distrust of the ability of governments and industry to resolve these interconnected challenges (Renting, Schermer, \& Rossi, 2012).

In response to these discontents, researchers, civil society organizations, and social movements have mobilized at multiple scales to develop viable solutions to transform food systems (HoltGiménez \& Shattuck, 2011; Levkoe, 2014). Instead of treating the symptoms and addressing issues in isolation, there has been widespread interest in addressing food as an interconnected system and as a basic human right. The food sovereignty movement has galvanized these ideals and mobilized people from across the globe toward the right of all people to "healthy and culturally appropriate food produced through ecologically sound and sustainable methods" (Declaration of Nyéléni, 2007). Moving beyond isolated food-related issues, food sovereignty is rooted in peasant and Indigenous ideals and uses a systems lens to advocate for communities to have self-determination and for those that produce, harvest, and consume food to reclaim power and control within their food systems (Jarosz, 2014; Patel, 2009).

A prominent approach to finding solutions to the systemic social, ecological, and economic problems in the food system has come in the form of food policy councils that aim to provide a forum to address food systems issues and a platform for coordinated action among multisectoral stakeholders (Blay-Palmer, 2009; Harper, Alkin, Shattuck, Holt-Giménez, \& Lambrick, 2009; Scherb, 2012). Food policy councils focus on public engagement in policy-making processes, often emphasizing opportunities for more participatory forms of democracy and engagement (Koc, McRae, Desjardins, \& Roberts, 2008) along with meaningful participation (Barling, Lang, \& Caraher, 2002; MacRae, 2011). As an approach to food policy development, these processes are rooted in systems thinking, which recognizes the interconnections between environmental, social, and economic factors and a whole-of-government approach that has been termed a "joined-up food policy" (Lang, 2009). While diverse in structure, most food policy councils aim to evaluate, influence, and establish integrated policy and programs for healthy, equitable, and sustainable food systems for the local municipality or region they are representing.

Despite the success and expansion of food policy councils across North America and the message of inclusivity, Kepkiewicz et al. (2015) caution that the uncritical acceptance of inclusive processes they assert can "re-inscribe privilege rather than redress the inequities that characterize the contemporary food system" (p100). They go on to suggest that "when activists (and, in particular, white, middle-class, settler activists) talk about including diverse groups, they can reinforce preconceived notions of who 'needs help' and who are the helpers" (p. 100). The implication here is that beyond just talking about inclusivity, food policy councils must move past a simple inclusion of marginalized groups and approach their work within decolonial and anti-oppressive frameworks (Curran \& González, 2011). For example, the main objective of the Detroit Food Policy Council has been to address racial and economic disparities throughout the food system, including combatting structural racism (Harper et al., 2009).

The TBAFS is a food policy council that promotes regional food self-reliance, healthy environments, and thriving economies through the implementation of research, planning, policy, and program development (TBAFS, n.d.-a). Following extensive public consultations and ongoing collaboration, a food charter was developed in 2008 
identifying a common vision, and in 2014 a strategic action plan was endorsed by seven municipalities in the Thunder Bay area. The TBAFS is organized around seven pillars identified and selected at a Community Food Summit held in March 2013: (1) food access, (2) forest and freshwater foods, (3) food infrastructure, (4) food procurement, (5) food production, (6) school food environments, and (7) urban agriculture (TBAFS, n.d.-b). Today, the TBAFS is an active and vibrant initiative, made up of over 40 organizational representatives, 10 executive council members, and seven regional municipalities.

TBAFS members include representatives from the Thunder Bay and rural municipal councils, public institutions, academics, farmers, local business, and nonprofit organizations. The council members are conveners and activators who collaboratively implement the priorities of the Thunder Bay Food Charter to develop and monitor a healthy, equitable, and sustainable food system. The food charter presents a vision of the values, principles, and priorities of regional food systems and has been endorsed by the city of Thunder Bay and local governments, businesses, and organizations. For example, the food access pillar calls for all community members to have regular access to adequate, affordable, nutritious, safe, and culturally appropriate food in a dignified way. The forest and freshwater foods pillar acknowledges the kinds of foods available in the Thunder Bay area and their connection to ecological sustainability, economic opportunities, and peoples' cultures and identity. The TBAFS executive undertakes the coordination and support of pertinent research and events to promote the mission and address gaps in the current food system. Recent examples include a partnership with the city to increase local food procurement through a food and agriculture market study to determine local food demand. The TBAFS is also largely involved in influencing food-related policy by building relationships between people and organizations at local and regional levels.

Despite being a highly active and engaged food policy council, the TBAFS had no formal engagement with Indigenous peoples or First Nations. Recognizing this, and being in a place to reflect on the next stages of its work, the TBAFS decided to ensure that at least one executive position would be held by an Indigenous representative. While this decision was a valuable step, it became abundantly clear that one individual could not represent the wealth of history and culture, and the needs of the diverse Indigenous communities in the region. With a unique opportunity to explore food as a tool for reconciliation and resurgence, the TBAFS came to understand the engagement gap and that Indigenous perspectives were an essential element in the future of Thunder Bay's food system. However, a meaningful partnership needed to be built on respect for Indigenous peoples' self-determination and significant efforts to strengthen the strained Indigenous-settler relations in the city, the region, and beyond.

Taking direction from its membership, the executive of the TBAFS began to focus more directly on developing partnerships with Indigenous leaders and organizations to better understand the needs of Indigenous peoples along with their perceived barriers and opportunities to engagement. The manifestation of these efforts was enthusiastic support for the development of the Indigenous Food Circle. Facilitated by Jessica and Charles, both TBAFS executive members, the process involved reaching out to Indigenous-led and Indigenous-serving organizations in the Thunder Bay area that were engaged in food systems efforts. This meant working with existing partners, drawing on personal contacts, and identifying new organizations to approach as a way to build relationships based on mutual respect and trust. The process began with a series of one-on-one conversations with organizational representatives to assess interest in the initiative, as well as a series of meetings of the larger group to establish a basis for cooperation. While some of these conversations took a more formal tone, others were deliberately unstructured and occurred over tea or a walk through the woods. This research was intentionally approached through taking leadership from those directly involved in and with Indigenous food systems. The result was the establishment of the Indigenous Food Circle that aimed to reduce Indigenous food insecurity, increase food self-determination, and establish a space to further explore the intersections of Indigenous and settler 
relationships and responsibilities as they relate to land and food.

\section{The Emerging Indigenous Food Circle: Food Policy Councils, Indigenous Peoples, Reconciliation and Resurgence}

The exploratory phase that preceded the establishment of the Indigenous Food Circle involved reaching out to Indigenous organizations with support from other members of the TBAFS executive, community members, and Lakehead university faculty and students. To support these efforts, the group applied for a small grant from the Social Science and Humanities Research Council of Canada (SSHRC) that provided support for collaborative research activities to inform decisionmaking. SSHRC's Partnership Engage grants are intended to address organizational needs and challenges and to "let non-academic organizations and postsecondary researchers access each other's unique knowledge, expertise and capabilities on topics of mutual interest" (SSHRC, n.d., p. 2).

Successfully receiving the grant enabled a continued exploration into the kinds of activities being undertaken by Indigenous organizations involved in food systems initiatives in the Thunder Bay area and how the TBAFS could better engage with these initiatives and build partnerships that were relevant to Indigenous peoples. The initial phase of the Indigenous Food Circle's development involved reaching out to Indigenous-led organizations already administering or developing foodrelated programs and initiatives along with other organizations that supported Indigenous peoples. The work privileged knowledge exchange activities that were both personal and meaningful, but that were notably different from the meetings and engagement sessions that established the TBAFS. For example, engagement included a series of ongoing, participatory conversations led by Indigenous people to establish trust-based relationships. All the initial meetings were focused on building relationships rather than strictly on gathering information. At their core, these efforts were premised on the idea that building sustainable food systems in the Thunder Bay area should be rooted in social justice and that Indigenous peoples be positioned to take leadership roles. Some organizations scheduled follow-up meetings to include other employees in the conversations to discuss food work that the particular organization was administering. These efforts employed an Indigenous research and pedagogical practice through a process of learning while doing, allowing for knowledge to freely emerge in an ethical process of embodied and relational knowledge co-production (Chilisa, 2011; Ray, 2012).

A summary of the information gathered was presented back to participants through one-on-one meetings and at a meeting of the Indigenous Food Circle to determine next steps. The results were also presented through a series of articles in the TBAFS newsletter and publications of member organizations, a final report, conference presentations, and a series of public events. From this exploratory research, participants determined that the primary aims of the Indigenous Food Circle should be to reduce Indigenous food insecurity, increase food self-determination, and establish meaningful relationships with the settler population through food. To do this, the group aspired to understand better the issues that affect Indigenoussettler relations and Indigenous peoples' foodrelated needs. The Indigenous Food Circle was given the mandate to establish a collaborative platform to support food-related initiatives developed by and for Indigenous organizations in the Thunder Bay area. Further, the following six objectives were adopted by the group:

1. To build meaningful relationships among Indigenous-led food organizations in the Thunder Bay area;

2. To support, connect, and coordinate members with food-related initiatives and opportunities;

3. To establish a space for Indigenous people to share information and develop solutions to address immediate needs and decolonize the food system;

4. To increase awareness of Indigenous organizations and the food-related work they are involved with;

5. To build relationships between Indigenousled and settler-led organizations; and, 


\section{To support effective Indigenous engage- ment and decolonization work in the city of Thunder Bay and the surrounding area.}

At the time of this writing, representatives from 22 organizations have committed to participate in the Indigenous Food Circle. In addition, 40 meetings were held with other Indigenous and/or supporting organizations that have expressed interest but need a clearer mandate before proceeding with full commitment. In 2018, the Indigenous Food Circle and the TBAFS co-developed a number of small pilot projects that aimed to support member organizations. For example, in 2017 and 2018, the Thunder Bay Country Market and the Indigenous Food Circle hosted members of the Anishnawbe Mushkiki Healthy Eating Active Living program for a cooking, learning, and sharing workshop to build familiarity with locally grown and harvested foods and the means of obtaining them. In 2018 and 2019, the Indigenous Food Circle supported a large-scale project in partnership with the Thunder Bay District Health Unit and Lakehead University to develop and implement food sovereignty visions for 14 First Nations in the Thunder Bay area (see Levkoe, McLaughlin, Strutt, $\& \mathrm{Ng}, 2019)$.

The initial research concluded that to build healthy, equitable, and sustainable food systems in the Thunder Bay area, it is essential to respect and make space for the leadership of Indigenous voices. Drawing on concepts of food sovereignty and emphasizing a re-connection to land-based food and political systems, the Indigenous Food Circle must continue to create space for Indigenous peoples to enact their own knowledge systems. Further, it was tasked with supporting and developing the capacity of Indigenous-led organizations to articulate and respond to relevant challenges and opportunities and to improve programming and policy in ways that assert Indigenous selfdetermination.

While there have been many reasons to celebrate, the journey to establish the Indigenous Food Circle has been complicated. The initial conversations with members of the TBAFS about the lack of Indigenous engagement were difficult and at times caused great discomfort among some members. Confronting issues of anti-Indigenous racism and acknowledging the impacts of settler colonialism take time and require great sensitivity, especially since a primary goal of the Indigenous Food Circle is to disrupt oppressive relationships between Indigenous and settler peoples in the Thunder Bay area, as well as recognizing and working to advance interrelated responsibilities. Moving through these conversations has involved a series of focused discussions along with targeted antiracism and anti-oppression trainings held for the TBAFS executive and member organizations. Another major challenge involved the lack of resources and time to conduct the research and work required to build trusting and meaningful relationships. Every individual and organization involved has indicated that they are overworked and many are participating "off the side of their desks." Finding additional supports and resources will be essential for further engagement. A third and related challenge has been that many of the Indigenous-led and Indigenous-serving organizations involved in the Indigenous Food Circle work with populations facing extremely high levels of historical and ongoing trauma and could barely keep up with addressing immediate needs. For some, understanding the prospects that food sovereignty had to offer was well beyond their capacity. In many cases, it was junior staff who attended meetings and contributed to the Indigenous Food Circle, indicating that more work needs to be done to engage upper-level management and organizational directors. Finally, while all participants agreed that the Indigenous Food Circle was much needed and had a vital role to play in the Thunder Bay area, there was, and remains, uncertainty and disagreement as to what should be the primary focus of the collective work. For example, there has been some tension around whether future efforts should focus on addressing immediate, short-term needs, or considering longer-term, policy-level change. Also, some priority issues identified by members (such as access to wild game and other Traditional foods) have been contentious and require further research and careful negotiation with municipal and regulatory bodies. Many of the challenges identified here are ongoing and will be part of the processes of collaborative dialogue 
within the Indigenous Food Circle.

Since the initiative began, the Indigenous Food Circle has already generated great interest, particularly for those engaged in food systems research and practice. As a result, the group has been invited to bring an Indigenous perspective to food systems work across the Thunder Bay area and beyond. This has included processes of engagement and sharing through providing regular updates to the TBAFS executive and presentations to the TBAFS council members at the annual general meeting. In October 2017, the Indigenous Food Circle and TBAFS were invited to present at the provincial Bring Food Home Conference in Ottawa, Ontario, and in November 2018, Jessica, the coordinator, represented the Indigenous Food Circle at the $10^{\text {th }}$ Food Secure Canada national assembly. These presentations focused on food sovereignty and issues surrounding reconciliation and resurgence through food in Northwestern Ontario. The Indigenous Food Circle has also taken on leadership through a number of other initiatives, including a scan of Indigenous procurement policies in partnership with the city of Thunder Bay and an initiative to build and support food sovereignty networks across Northwestern Ontario. Moving forward, it aims to facilitate more discussions around the topic of decolonization and Indigenous food sovereignty and has already partnered with the TBAFS to develop and deliver antiracism and anti-oppression trainings in Thunder Bay. For now, the Indigenous Food Circle and the TBAFS have agreed to remain distinct. The Indigenous Food Circle has its own coordinator and is in the process of developing an independent governance structure and terms of reference rooted in Indigenous ideals of self-determination. However, both groups plan to explore co-governance mechanisms and further opportunities for mutual support in the future.

\section{Conclusions}

While there are many examples of initiatives that are creating on-the-ground change in local communities, to have an impact on the dominant food system, those involved must also work together to share experiences, successes, and challenges and collaboratively address the root causes of social inequity. Considering the ongoing strain on Indigenous-settler relationships in the Thunder Bay area, the Indigenous Food Circle presents a unique opportunity to demonstrate ways that food can be used as a tool for reconciliation and resurgence. The Indigenous Food Circle was built on the idea that Indigenous peoples should have control of their food systems and is rooted in the theory and practice of food sovereignty, emphasizing selfdetermination and a re-connection to land-based food systems.

While only in the beginning stages, the Indigenous Food Circle is committed to confronting colonial histories, learning from other Indigenous food sovereignty efforts, and engaging in action that transforms relationships. The aim for the next stage of work will be to provide enhanced capacity to reflect on the challenges and opportunities to improve programming and policies that embody principles of Indigenous food sovereignty. This will involve further engagement with the different Indigenous- and settler-led organizations involved in food systems initiatives in the Thunder Bay area and across Northwestern Ontario. These efforts will also involve further exploration of ways the TBAFS can learn from and participate in exchanges and partnerships with the Indigenous Food Circle. In addition, this work demands deeper engagement and education with settler organizations to further understand attempts at reconciliation and to support them in applying a decolonizing approach to servicing and working with Indigenous people in the Thunder Bay area. However, we caution that the success of the Indigenous Food Circle requires more than simply goodwill from TBAFS members and other allied organizations. It demands confronting the ongoing legacy of colonialism, land dispossession, antiIndigenous racism, and violence in the city of Thunder Bay, and engaging in action that transforms these relations. It means embracing the discomfort that comes with recognizing the prevalence of settler colonialism and developing respectful and just relationships followed by action. 


\section{Acknowledgments}

We are grateful to all the organizations and individuals that have committed to support the efforts of the Ingenious Food Circle. We want to express our thanks to the many people that contributed to the research and editing of this paper, including Cheryl Suggashie, Joyce Hunter, Michaela Bohunicky, Karen Kirk, Victoria Pullia, and members of the Indigenous Food Circle and the Thunder Bay and Area Food Strategy.

\section{References}

Barling, D., Lang, T., \& Caraher, M. (2002). Joined-up food policy? The trials of governance, public policy and the food system. Social Policy \& Administration, 36(6), 556-574. https://doi.org/10.1111/1467-9515.t01-1-00304

Blay-Palmer, A. (2009). The Canadian pioneer: The genesis of urban food policy in Toronto. International Planning Studies, 14(4), 401-416. https://doi.org/10.1080/13563471003642837

Chilisa, B. (2011). Indigenous research methodologies. Los Angeles: SAGE.

City of Thunder Bay. (2015). Strategic Plan. Retrieved from https://www.thunderbay.ca/en/city-hall/resources/Documents/Strategic-Plan/Key'TrendsandIndicators.pdf

Council of Canadian Academies. (2014). Aboriginal food security in northern Canada: An assessment of the state of knowledge. Ottawa. The Expert Panel on the State of Knowledge of Food Security in Northern Canada, Council of Canadian Academies. Retrieved from https://cca-reports.ca/reports/aboriginal-food-security-in-northern-canada-anassessment-of-the-state-of-knowledge/

Curran, C. J., \& González, M. T. (2011). Food justice as interracial justice: Urban farmers, community organizations and the role of government in Oakland, California. The University of Miami Inter-American Law Review, 43(1), $207-232$. https://repository.law.miami.edu/umialr/

Dachner, N., \& Tarasuk, V. (2018). Tackling household food insecurity: An essential goal of a national food policy. Canadian Food Studies/La Revue canadienne des études sur l'alimentation, 5(3), 230-247. https://doi.org/10.15353/cfs-rcea.v5i3.278

Daschuk, J. W., (2013). Clearing the plains: Disease, politics of starvation, and the loss of Aboriginal life. Regina, Saskatchewan: University of Regina Press.

Declaration of Nyéléni. (2007). Forum for food sovereignty synthesis report. Retrieved from https://nyeleni.org/spip.php?article334

Dowler, E. A., \& O'Connor, D. (2012). Rights-based approaches to addressing food poverty and food insecurity in Ireland and UK. Social Science \& Medicine, 74(1), 44-51. https://doi.org/10.1016/i.socscimed.2011.08.036

Elsheikh, E. (2016). Race and corporate power in the US food system: Examining the farm bill. Dismantling Racism in the Food System, 2. Backgrounder series from Food First: Institute for Food \& Development Policy. Retrieved from https:// foodfirst.org/publication/race-and-corporate-power-in-the-us-food-system-examining-the-farm-bill/

Ericksen, P. J. (2008). Conceptualizing food systems for global environmental change research. Global Environmental Change, 18(1), 234-245. https://doi.org/10.1016/j.gloenvcha.2007.09.002

Food Secure Canada. (2011). Indigenous food sovereignty (Discussion paper 1). Montreal: Author. Retrieved from https://foodsecurecanada.org/sites/foodsecurecanada.org/files/DP1 Indigenous Food Sovereignty.pdf

Fort William First Nation [FWFN]. (2019). Our Traditional Territory. Retrieved from https://fwfn.com/departments/duty-to-consult-accommodate/

Frison, E. A., \& International Panel of Experts on Sustainable Food Systems [IPES]. (2016). From uniformity to diversity: A paradigm shift from industrial agriculture to diversified agroecological systems. Louvain-la-Neuve, Belgium: IPES. Retrieved from https://hdl.handle.net/10568/75659

Grey, S., \& Patel, R. (2015). Food sovereignty as decolonization: some contributions from Indigenous movements to food system and development politics. Agriculture and Human Values, 32(3), 431-444. https://doi.org/10.1007/s10460-014-9548-9

Harper, A., Alkon, A, Shattuck, A., Holt-Giménez, E., \& Lambrick, F. (2009). Food policy councils: Lessons learned. Retrieved from the Food First website: https:/ foodfirst.org/publication/food-policy-councils-lessons-learned

Holt-Giménez, E., \& Shattuck, A. (2011). Food crises, food regimes and food movements: rumblings of reform or tides of transformation? Journal of Peasant Studies, 38(1), 109-144. https://doi.org/10.1080/03066150.2010.538578 
Howard, A., \& J. Edge. (2013). Enough for all: Household food security in Canada. Ottawa: The Conference Board of Canada. Retrieved from the Thunder Bay and Area Food Strategy website: http://tbfoodstrategy.ca/files/3514/4623/0536/CBC report on food security.pdf

Indigenous Food Systems Network. (n.d.). Indigenous land and food systems. Retrieved from https://www.indigenousfoodsystems.org

Indigenous Food Systems Network. (n.d.). Indigenous food systems network. Indigenous Food Systems Network website: https://www.indigenousfoodsystems.org

International Assessment of Agricultural Knowledge, Science and Technology for Development [IAASTD]. (2009). Agriculture at a crossroads: Synthesis report. Washington, D.C.: IAASTD. Retrieved from http://hdl.handle.net/20.500.11822/7862

Jarosz, L. (2014). Comparing food security and food sovereignty discourses. Dialogues in Human Geography, 4(2), $168-181$. https://doi.org/10.1177/2043820614537161

Kepkiewicz, L., Chrobok, M., Whetung, M., Cahuas, M., Gill, J., Walker, S., \& Wakefield, S. (2015). Beyond inclusion: Toward an anti-colonial food justice praxis. Journal of Agriculture, Food Systems, and Community Development, 5(4), 1-6. https://doi.org/10.5304/jafscd.2015.054.014

Koc, M., MacRae, R., Desjardins, E., \& Roberts, W. (2008). Getting civil about food: The interactions between civil Society and the state to advance sustainable food systems in Canada. Journal of Hunger \& Environmental Nutrition, 3(2/3), 122-144. https:// doi.org/10.1080/19320240802243175

Lakehead Social Planning Council [LSPC]. (2018). Building a better Thunder Bay for all: $A$ community action plan to reduce poverty 2018-2020. Thunder Bay, ON: LSPC. Retrieved from https://www.lspc.ca/wp-content/uploads/2018-Poverty-Reduction-Strategy.pdf

Lang, T. (2009). Reshaping the food system for ecological public health. Journal of Hunger and Environmental Nutrition, 4(3-4), 315-335. https://doi.org/10.1080/19320240903321227

Lang, T., \& Heasman, M. (2015). Food wars: The global battle for mouths, minds and markets. New York: Routledge.

Lawrence, G., Richards, C., \& Lyons, K. (2013). Food security in Australia in an era of neoliberalism, productivism and climate change. Journal of Rural Studies, 29, 30-39. https://doi.org/10.1016/j.jrurstud.2011.12.005

Levkoe, C. Z. (2011). Towards a transformative food politics. Local Environment: The International Journal of Justice and Sustainability, 16(7), 687-705. https://doi.org/10.1080/13549839.2011.592182

Levkoe, C. Z. (2014). The food movement in Canada: A social movement network perspective. Journal of Peasant Studies, 41(3), 385-403. https://doi.org/10.1080/03066150.2014.910766

Levkoe, C. Z., McLaughlin, J., Strutt, C., \& Ng, V. (2019). Understanding our food systems: Building food sovereignty in northwestern Ontario, Phase II Final Report. Retrieved from the Sustainable Food Systems Lab website: https:// foodsystems.lakeheadu.ca/wp-content/uploads/2019/04/Understanding-Our-Food-Systems-2Final March-2019.pdf

Levkoe, C. Z., \& Sheedy, A. (2019). A people-centred approach to food policy making: Lessons from Canada's people’s food policy project. Journal of Hunger \& Environmental Nutrition, 14(3), 318-338. https://doi.org/10.1080/19320248.2017.1407724

MacRae, R. (2011). A joined-up food policy for Canada. Journal of Hunger \& Environmental Nutrition, 6(4), $424-457$. https://doi.org/10.1080/19320248.2011.627297

Manuel, A., \& Derrickson, G. C. R. M. (2015). Unsettling Canada: A national wake-up call. Toronto: Between the Lines.

Martens, T., Cidro, J., Hart, M. A., \& McLachlan, S. (2015). Understanding Indigenous food sovereignty through an Indigenous research paradigm. Journal of Indigenous Social Development, 5(1), 18-37. https://ucalgary.ca/journals/indigenous-social-development

Martin, D. H. (2012). Two-eyed seeing: A framework for understanding indigenous and non-indigenous approaches to indigenous health research. Canadian Journal of Nursing Research, 44(2), 20-42.

Matties, Z. (2016). Unsettling settler food movements: Food sovereignty and decolonization in Canada. Cuizine: The Journal of Canadian Food Cultures/Cuizine: Revue des cultures culinaires au Canada, 7(2). https://doi.org/10.7202/1038478ar 
McNeilly, G. (2018). Broken trust: Indigenous people and the Thunder Bay Police Service. Retrieved from the Office of the Independent Police Review Director website: http://oiprd.on.ca/wp-content/uploads/OIPRD-BrokenTrust-Final-Accessible-E.pdf

Milloy J. S. (1999). A national crime: The Canadian government and the residential school system, 1879 to 1986. Winnipeg: University of Manitoba.

Morrison, D. (2011). Indigenous food sovereignty: A model for social learning. In H. Witman, A. A. Desmarais, \& N. Wiebe (Eds.), Food sovereignty in Canada: Creating just and sustainable food systems (pp. 97-113). Halifax, Nova Scotia: Fernwood.

Patel, R. (2009). Food sovereignty. Journal of Peasant Studies, 36(3), 663-706. https://doi.org/10.1080/03066150903143079

Pechlaner, G., \& Otero, G. (2010). The neoliberal food regime: Neoregulation and the new division of labor in North America. Rural Sociology, 75(2), 179-208. https://doi.org/10.1111/j.1549-0831.2009.00006.x

Pellow, D. N. (2016). Toward a critical environmental justice studies: Black Lives Matter as an environmental justice challenge. Social Science Review on Race, 13(2), 282-294. https://doi.org/10.1017/S1742058X1600014X

Power, E. M. (2008). Conceptualizing food security for Aboriginal people in Canada. Canadian Journal of Public Health/Revue Canadienne de sante'e publique, 99(2) 95-97. https://doi.org/10.1007/BF03405452

Ray, L. (2012). Deciphering the "Indigenous" in Indigenous methodologies. Alternative: An International Journal of Indigenous Peoples, 8(1), 85-98. https://doi.org/10.1177/117718011200800107

Ray, L., Burnett, K., Cameron, A., Joseph, S., LeBlanc, J., Parker, B., Recollet, A., \& Sergerie, C. (2019). Examining Indigenous food sovereignty as a conceptual framework for health in two urban communities in Northern Ontario, Canada. Global Health Promotion, 26(Suppl. 3), 54-63. https://doi.org/10.1177\%2F1757975919831639

Renting, H., Schermer, M., \& Rossi, A. (2012). Building food democracy: Exploring civic food networks and newly emerging forms of food citizenship. International Journal of Sociology of Agriculture and Food, 19(3), 289-307. https://www.isa-agrifood.com/ijsaf-v19-3-289-307

Rideout, K., Riches, G., Ostry, A., Buckingham, D., \& MacRae, R. (2007). Bringing home the right to food in Canada: Challenges and possibilities for achieving food security. Public Health Nutrition, 10(6), 566-573. https://doi.org/10.1017/S1368980007246622

Robidoux, M., LeBlanc, J., \& Mason, C. (2017). Conversations with Wawakapewin Elder Simon Frogg. In M. Robidoux \& C. Mason (Eds.), A land not forgotten: Indigenous food security and land-based practices in Northern Ontario (pp. ix-xvi). Winnipeg: University of Manitoba Press.

Rosin, C. (2013). Food security and the justification of productivism in New Zealand. Journal of Rural Studies, 29, 50-58. https://doi.org/10.1016/j.jrurstud.2012.01.015

Rudolph, K. R., \& McLachlan, S. M. (2013). Seeking Indigenous food sovereignty: Origins of and responses to the food crisis in northern Manitoba, Canada. Local Environment, 18(9), 1079-1098. https://doi.org/10.1080/13549839.2012.754741

Scherb, A., Palmer, A., Frattaroli, S., \& Pollack, K. (2012). Exploring food system policy: A survey of food policy councils in the United States. Journal of Agriculture, Food Systems, and Community Development, 2(4), 3-14. https://doi.org/10.5304/jafscd.2012.024.007

Sinclair, M. (2018). Thunder Bay Police Services Board Investigation: Final report. Retrieved from the Tribunals Ontario Safety, Licensing Appeals, and Standards Division website: https://slasto-tsapno.gov.on.ca/ocpc-ccop/en/investigative-division/reports/

Social Science and Humanities Research Council of Canada [SSHRC]. (n.d.). Partnership Engage grants. Retrieved from http://www.sshrc-crsh.gc.ca/funding-financement/programs-programmes/partnership engage grantssubventions d engagement partenarial-eng.aspx

Statistics Canada. (2017a). Aboriginal peoples in Canada: Key results from the 2016 Census. Retrieved from https://www150.statcan.gc.ca/n1/daily-quotidien/171025/dq171025a-eng.htm

Statistics Canada. (2017b). Police reported crime statistics in Canada. Retrieved from https://www150.statcan.gc.ca/n1/pub/85-002-x/2018001/article/54974-eng.htm

Thunder Bay and Area Food Strategy [TBAFS]. (n.d.-a). About. Retrieved from http://tbfoodstrategy.com/about/ TBAFS. (n.d.-b). Pillars. Retrieved from http://tbfoodstrategy.com/pillars/ 